\title{
Discurso E MEMÓRIA: IDENTIDADE NA LÍNGUA, nO Tempo E No ESPAÇO
}

\author{
Doris Natia Cavallari \\ Giliola Maggio
}

RESUMO O texto traça o percurso dos imigrados de Pedrinhas Paulista, seu processo de adaptação e de apreensão da nova língua, permeado pelo discurso do padre, Dom Ernesto, uma das figuras centrais da comunidade pedrinhense. Além disso, são analisados textos escritos por ele, elaborados no intuito de manter seus fiéis unidos.

PALAVRAS-CHAVE língua; discurso; identidade; memória; imigração. 
ABSTRACT Il testo traccia il percorso degli immigrati di Pedrinhas Paulista, il loro processo di adattamento e di apprendimento della nuova lingua, permeato dal discorso del parroco, Don Ernesto, una delle figure centrali della comunità predrinhense. Oltre a ciò, sono analizzati dei testi scritti da lui, allo scopo di mantenere uniti i fedeli.

PAROLE CHIAVE lingua; discorso. identità; memoria; immigrazione.

ABSTRACT This paper looks into the journey of Pedrinhas Paulista's immigrants, their process of adaptation and acquisition of the new language, enriched by the discourse of Priest Dom Ernesto, a pivotal character in the local community. Furthermore, the paper looks into texts authored by him in an attempt to keep his congregation together. KEYWORDS language; discourse; identity; memory; immigration. 


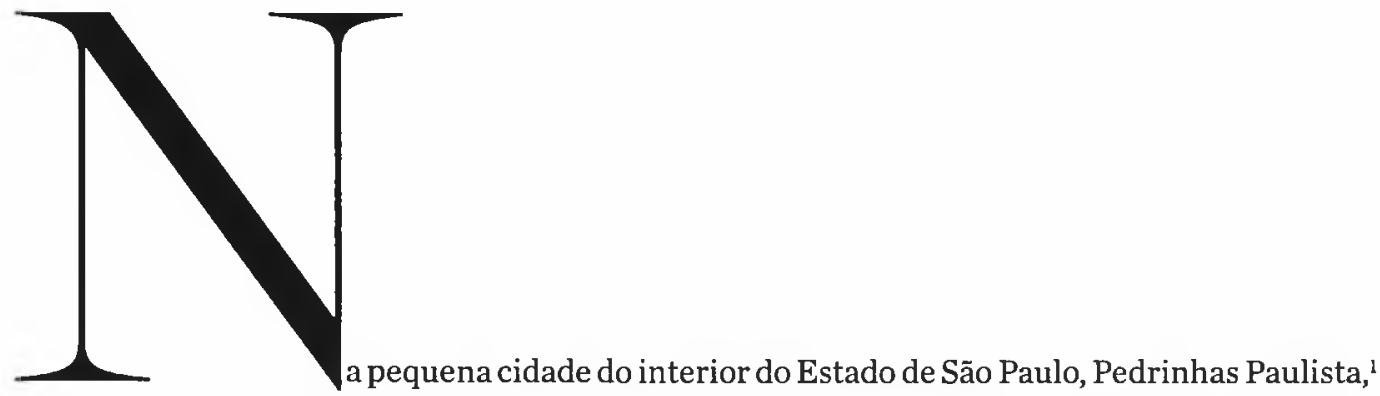
originada de uma Colônia formada por imigrados italianos, identificamos elementos ligados à problemática de sua inserção num ambiente totalmente diverso daquele de origem e de como ocorre a construção da identidade através do espaço e da língua.

A Colônia é fruto de um acordo assinado em outubro de 1949, que regularizava todas as pendências entre os o Brasil e a Itália ocorridas em conseqüência da Segunda Guerra Mundial, e acionava o tratado de paz de 10 de fevereiro de 1947, desvinculando todos os bens italianos bloqueados pelo governo brasileiro durante a Guerra, sob a condição de que fossem usados para compra de terras e infra-estruturas em projetos de colonização. A Itália enviaria agricultores para colonizar áreas destinadas ao cultivo.

Os imigrantes, ao deixarem a Pátria, tinham idealizado uma imagem do Brasil que, na maioria das vezes, era fabricada pelos agentes interessados em reunir mão-de-obra para a emigração. As informações obtidas pelos imigrantes normalmente eram tendenciosas e criavam, dessa forma, um país que na realidade não existia.

O material que coletamos entre os anos de 1999 e 2000, em Pedrinhas Paulista, compreende 45 entrevistas ${ }^{2}$ com o grupo de imigrantes anciãos e seus filhos nascidos na Itália; 115 questionários destinados aos filhos e netos, nascidos no Brasil; 98 redações elaboradas por estudantes (descendentes de italianos e não-descendentes) do Ensino Fundamental e Médio da cidade, confrontadas com redações de mesmo tema coletadas, em 1965, pelo antropólogo João Baptista Borges Pereira, para sua pesquisa de Doutoramento. Entretanto, nos deteremos fundamentalmente em trechos

1. Pedrinhas Paulista localiza-se na Bacia do Paranapanema, na direção Sudoeste do Planalto Paulista, na região da Alta Sorocabana, aproximadamente a $550 \mathrm{~km}$ da Capital Paulista; faz limites com os municípios de Cruzália, Florínea e Maracai, no Estado de São Paulo e com o município de Sertaneja, no Estado do Paraná;

2. Dos 45 entrevistados, 25 pertencem ao grupo dos mais velhos e 20 ao grupo dos que chegaram à Colônia ainda jovens e crianças; desses imigrantes, 24 são provenientes do Vêneto, 11 do Lazio, dois do Abruzzo, dois do Trentino, um da Lombardia, um da Emilia Romagna, um da Calabria, um do Friuli, um da Umbria e um da Puglia; o grupo dominante na comunidade é originário do Lazio, seguido pelo grupo Vêneto e Abruzzo. Predomina nos dois grupos a agricultura como profissão, para os homens, e as mulheres são donas-de-casa; são exceçōes o farmacêutico c a farmacêutica, os comerciantes (três), a costureira, a pequena empresária e o diretor da Cooperativa. 
retirados das entrevistas, ${ }^{3}$ a fim de analisar elementos relativos aos discursos do padre, guia espiritual e ideológico do grupo de imigrantes, cujos conteúdos recorrem na fala dos italianos da antiga Colônia e seus descendentes. O material restante nos servirá como complemento para que possamos compor o quadro geral da comunidade.

Encontramos nos testemunhos orais dos italianos de Pedrinhas Paulista alusões à terra prometida, imagem mitizada e construída pela forte propaganda publicitária exercida no país de origem, a fim de convencê-Jos a emigrar. O novo lugar era idealizado como se fosse o paraíso, espaço que precisava ser trabalhado pelo homem. Tal visão emana dos relatos dos italianos pedrinhenses e coloca o imigrante quase como um herói desbravador. Entretanto, é necessário ressaltar que a primeira impressão para a maioria foi negativa, ao constatar a dificuldade de inserção no novo país e o sentimento de perda ao ter de deixar para trás a própria aldeia e, muitas vezes, entes queridos.

Foram inúmeras as dificuldades encontradas no primeiro contato com a nova terra, como a discrepância entre as dimensões e a paisagem italiana e brasileira; a diversidade do agrupamento humano; diferenças do clima, da cor da terra (esta região é famosa por sua terra vermelha) e da água. Ainda hoje os imigrantes recordam-se e confrontam como contrastavam as cores escuras do solo de Pedrinhas e de sua água com a alvura da terra e a cristalinidade da água da aldeia. No relato intenso, principalmente das mulheres, ressaltam-se os dois mundos: o abandono do branco da paz para enfrentar o vermelho, representativo da luta e do sofrimento na adaptação ao novo lugar. Tais elementos remetem à saudade de sua aldeia, acolhedora e aconchegante, contraponto fundamental ao novo lugar, sentido árido e distante.

À sua chegada, os imigrantes eram recebidos, no período da seca, pela poeira vermelha levantada pelo vento e o excessivo calor; na época das chuvas, pela "lama grudenta como cola", como alguns a descrevem. A esperá-los estavam os dirigentes da Companhia, o padre, os italianos bem-sucedidos (ou mais resignados), recebendo-os com frases como: "estamos muito bem!", "vocês não vão se arrepender de ter vindo para cá" “verão como fizeram bem em vir!”, dentre outras palavras de apoioe encorajamento, demonstrando o bem-estar de todos e, na maioria das vezes, ocultando o verdadeiro sentimento que os afligia. Observamos, na composição da cena da chegada das novas famílias, o quadro de uma comunidade feliz, da família reunida, que luta e encoraja a vencer as adversidades.

O destino de Pedrinhas, entretanto, era de outra sorte. A cidade idealizada e construída para fins produtivos e lucrativos, localizada próxima a grandes rodovias, tem hoje seus produtos agrícolas facilmente escoados. A Cooperativa, situada estrategicamente à entrada principal da cidade, dá a dimensão de sua importância enquanto elemento centralizador da economia. Duas avenidas principais, a "Brasil" (por onde se tem acesso ao centro urbano, composta por duas pistas mediadas por um canteiro central) e a "Itália", representam no espaço o encontro e o entrelaçamento de dois povos e de duas culturas.

Ainda hoje a Igreja é uma das únicas representações que espelha com clareza a realidade na qual se localiza o imigrante pedrinhense, apesar dos cinqüenta anos de imigração.

3. Para a transcriçāo do material foram utilizadas as regras do projeto NURC - Projeto de Estudo da Norma Urbana Lingüística Culta; entretanto, nos trechos mencionados neste texto foram usados apenas alguns sinais de transcrição, tais como parênteses (trecho não compreendido ou não mencionado); reticências (pausa); ponto de interrogação. A fala do entrevistador foi omitida propositadamente, a fim de ressaltar somente o conteúdo sob análise. A traduçăo procura manter-se fiel à fala original. 
O italiano de Pedrinhas Paulista, retirado de sua terra natal e destituído de suas regras sociais, foi inserido num ambiente onde as normas foram feitas para satisfazer uma comunidade italiana. Talvez por isso até hoje a idéia do "pedacinho da Itália no Brasil" ainda resista, reforçada pela reconstrução do imaginário social recriado fora da Península. Ao mesmo tempo em que perderam sua porção de aldeia, recriaram, em solo brasileiro, as regras italianas pedrinhenses, que perduram, passando de geração a geração.

Nas redações de 1965 e nas de 2000, são unânimes as opiniões positivas a respeito do padre. Ainda hoje ele é considerado o centro, a viga mestra da comunidade, e é sempre citado como o "chefe", o "detentor do poder" $\mathrm{e}$ "fundador de Pedrinhas". A figura do padre fundador, Dom Ernesto, teve um papel fundamental na questão da manutenção dos costumes, nos valores éticos e morais da comunidade, chegando a interferir pessoalmente e individualmente como conselheiro espiritual e muitas vezes como pai, em nome da manutenção de uma pureza étnica, que por vezes chegou a extremos. Sua figura mitificada aparece como controladora e autoritária. Sem dúvida, é o mais importante personagem da história dessa comunidade.

A Igreja é a primeira marca autêntica de tentativa de reconstrução de uma identidade italiana em Pedrinhas. Ergueu-se, contemporaneamente a ela, o campanário, alto, para chamar e reunir os fiéis para a missa. Durante anos a Igreja e o campanário foram os elementos que mais se destacaram no cenário urbano de Pedrinhas. A Igreja de "São Donato" foi assim denominada em homenagem ao padroeiro de San Donà di Piave, cidade de origem do padre e dos trinta primeiros imigrantes que iniciaram a construção da Colônia.

Nas missas dominicais, realizadas em italiano, até meados dos anos 70, os sermões de Dom Ernesto insistiam na força necessária aos imigrantes para suportar e superar obstáculos. Sua presença e sua atuação foram fundamentais para auxiliar na construção da imagem de uma pequena Itália por parte dos imigrantes de Pedrinhas.

A título de exemplo, destacaremos trechos de sermões do padre que uniam a mensagem religiosa às suas intenções de preservar o patrimônio cultural das famílias sob sua tutela. O culto religioso constituía o momento em que o reverendo se dirigia a todos os fiéis, indicando diretrizes de comportamento.

A análise que propomos para alguns dos textos de Dom Ernesto baseia-se, principalmente, nas idéias de Bakhtin para quem todo "signo é ideológico" (1991:31) e a palavra, que é sempre umideologema (1990:135), realiza a idéia do homem sobre seu mundo.

Dentre os conceitos de Bakhtin, interessa-nos aqui observar as diferenças de duas categorias que constam do capítulo IV, "A pessoa que fala no romance", de seu livro Questóes de literatura e estética: a teoria do romance (1990). Nesse capítulo, o crítico discute sobre formas de transmissão do discurso e chega a duas modalidades: a de palavra autoritária, típica das categorias ligadas ao poder (religiosa, política, moral, a palavra dos pais e professores, etc) - que "exige de nós o reconhecimento e a assimilação, ela se impõe a nós independentemente do grau de sua persuasão 
interior no que nos diz respeito, nós já a encontramos unida à autoridade" (1990:143) - e a de palavra interiormente persuasiva que "é metade nossa, metade de outrem" e nos revela possibilidades diferentes de significação, é a palavra "determinante para o processo da transformação ideológica da consciência individual” (1990:145).

A estes conceitos unem-se os de Perelman, ${ }^{4}$ estudioso belga que retoma e amplia os elementos básicos da retórica clássica para propor sua "nova retórica" e que afirma que a linguagem não é apenas um meio de comunicação, mas um instrumento de persuasão e convencimento. Em seu tratado, o crítico observa: "Propomo-nos chamar persuasiva a uma argumentação que pretende valer só para um auditório particular e chamar convincente àquela que deveria obter a adesão de todo ser racional" (1996:31). O autor discute sobre a variação que pode haver entre os dois termos (persuasão e convencimento), comentando textos clássicos, como $A$ crítica da razão pura de Kant, entre outros. Interessa-nos, contudo, seu ponto de vista sobre a questão de persuadir, enquanto capacidade de fazer aceitar argumentos não apenas pela razão, mas por uma identificação com o orador.

Dom Ernesto serve-se essencialmente da palavra autoritária, que não admite questionamentos, para tornar persuasivo seu discurso e garantir seu lugar de liderança da comunidade de imigrantes. O padre domina o discurso religioso e privilegia-se dele para definir o comportamento ideológico, não só religioso, pois apela ao patriotismo e à necessidade de o grupo manter a própria identidade. Elemento fundador deste tipo de discurso é a revelação advinda da passagem de Cristo sobre a terra; o homem terá nela um modelo pela eternidade, pois todo futuro já está determinado pela revelação passada da verdade universal cristã.

Em discurso feito para comemorar a festa da Sagrada família de Nazaré, escrito em italiano em 1958 e adaptado e traduzido pelo próprio padre em duas ocasiões, em 1985, é possível observar como Dom Ernesto convida as famílias a manterem seus laços. Ele começa seu discurso, em 1958, falando da "capanna" (casebre) e depois da "umile casetta" que encontrará tradução literal na "humilde casinha". do texto de 1985. Nos textos em italiano e em português, o padre fala do retorno ao lar da sagrada família, após visita obrigatória ao templo para o ritual de purificação, quando Jesus completou 12 anos, e afirma que naquele lar, onde "faltavam tantas coisas", reinava a paz, pois a alegria, Jesus, vivia nele.

Os textos exortam os fiéis a tomarem como "modelo" aquela família, em que a mãe "é a verdadeira dona da casa e vive para a família", o pai é "homem justo e venerando, indefesso trabalhador que, com o suor de sua fronte, provê às necessidades da família" e o menino é o "sorriso dos pais, que cresce em bondade, sapiência e graça diante de Deus e dos homens" (1958 - tradução nossa).

Dom Ernesto, por várias vezes, enumera três características para ilustrar sua fala. $\mathrm{O}$ modelo a ser seguido é o da família de Jesus composta por pai, mãe e fillho (que cresce em bondade, sapiência e graça). Diz ainda que o que afasta Jesus das casas dos fiéis é a "blasfêmia dos pais, o desregramento dos filhos e, talvez, o pecado das mães"; apela ainda para a "serenidade, tranqüilidade,

4. PERELMAN, C. e OLBRECHTS-TYTECA, L. Tratado sobre a argumentą̧ão: a nova retórica. Trad. Maria E.G.G. Pereira. São Paulo: Martins Fontes, 1996. 
paz" que só poderão ser conquistadas pela comunidade dos italianos "exilados de sua terra natal" pela presença de Jesus.

Vemos que o padre formula seu texto utilizando-se muito do número três, caro aos cristãos, por relembrar a santíssima trindade e a perfeição divina. Eni Orlandi, em seu texto Discurso e texto: formulação e circulação dos sentidos ${ }^{5}$ observa:

Formular é dar corpo aos sentidos. E, por ser um ser simbólico, o homem constituindo-se em sujeito pela e na linguagem, que se inscreve na história para significar, tem seu corpo atado ao corpo dos sentidos. Sujeito e sentido constituindo-se ao mesmo tempo têm sua corporalidade articulada no encontro da materialidade da língua com a materialidade da história. (2001:9)

História que, no parecer do padre, deve ser escrita segundo modelo divino, cujo exemplo na terra foi dado pela harmonia da santa família.

Além de procurar, com seu sermão, manter unidas as famílias, base da estrutura social, o sacerdote refere-se aos fiéis como "emigrantes" ( 6 anos após sua vinda para o Brasil) e "exilados" em discurso feito em língua italiana, para reforçar aos fiéis a necessidade de não esquecer suas origens e sua identidade. Ele termina seu discurso dizendo:

Quest’anno abbiamo un motivo tutto speciale per celebrare con festa questa festa, siamo emigranti, siamo per così dire in esilio in cerca di pane e lavoro e quale cumulo di sacrifici, quale cumulo fatiche disumane a noi! E bene, sappiate che proprio per noi, proprio per le famiglie degli emigranti il papa ha dato come esempio, modello di sostegno, la santa famiglia di Nazareth. Specchiamoci in quello, imitiamo quella, facciamo che Gesù segni nelle nostre case e state certi ritornerà la serenità, la tranquilità e la pace. ${ }^{6}$ (grifos nossos)

Dom Ernesto termina seu sermão com uma exortação utilizando-se do modo imperativo (espelhemos, imitemos, façamos, fiquem - verbos grifados no texto original) e do estilo paratático; usa a palavra autoritária, pela alusão a uma fé em algo maior e não pela racionalidade. Mas, ao mesmo tempo, usa os termos "emigrantes e exilados" retomando uma realidade histórica recente: a guerra e a destruição que obrigaram os homens a procurarem novas terras em busca de "pão e trabalho" e utiliza, ainda, a primeira pessoa do plural, "nós", de modo que, ao relembrar "quantos sacrifícios e esforços desumanos para nós". o padre insere-se nas lutas e compartilha os sentimentos dos "exilados italianos"

O reconhecimento do exílio, a percepção do afastamento e da nostalgia, do mal du pays, intensificam a sensação de deslocamento e o desejo impossivel do retorno imediato; esses fatores forne-

5. ORLANDI, E. Discurso e texto: formulação e circulação dos sentidos. Campinas/SP: Pontes, 2001.

6. "Este ano temos um motivo especial para celebrar esta festa, somos emigrantes, somos por assim dizer em exílio, em busca de pão e trabalho e quantos sacrifícios, quantos esforços desumanos para nós. Pois bem! Saibam que justamente para nós, justamente para as famílias de emigrantes o papa deu como exemplo, modelo de sustentação, a santa família de Nazaré. Espelhemo-nos nela, imitemo-la, façamos com que Jesus abençoe nossas casas e, fiquem certos, retornará a serenidade, a tranqüilidade, a paz" 
cem ao discurso de dom Ernesto duas direções. A primeira, da solidariedade ("pelos sacrifícios e esforços impostos a nós"), faz com que a sua seja a palavra interiormente persuasiva que "é metade nossa, metade de outrem" e nos revela possibilidades diferentes de significação, é a palavra "determinante para o processo da transformação ideológica da consciência individual” (1990:145).

Ao mesmo tempo, o termo "exílio", utilizado neste contexto (o sermão do padre durante a missa,) assume valor "cósmico", já que as condições de exílio, de nostalgia, de uma intensa necessidade de retorno às origens passam a ser, mais do que retorno à Itália, a necessidade de retorno ao "paraíso perdido". Os emigrados assumem, então, valor de "povo escolhido por Deus" que precisa superar as provas, para poder voltar ao lar divino; do mesmo modo, a voz de Dom Ernesto, o pastor, assume valor profético, ao recordar a essas almas o seu ponto de origem, não mais Itália, mas o reino de Deus. Os "emigrantes", como os chama dom Ernesto, são um povo de Deus, distante da sua terra, mas unido pela língua, pela cultura e pelos laços de família que devem espelhar-se no arquétipo, no melhor modelo para a humanidade: "a sagrada família".

Nos discursos de 1985, vinte e sete anos mais tarde, o padre já não fala em exílio e faz seu sermão em português, porque as exigências da colônia, agora rica e com inúmeros empregados brasileiros, são outras, mas convida os fiéis a serem pais mais atentos e a manterem a união da família, visto que as crises e tragédias ocorrem graças ao "desequilíbrio moral do mundo contemporâneo e à desintegração da família"

Nesses sermões, o reverendo alerta que os pais abandonaram as escolas da moralidade e da espiritualidade em nome da preocupação com a carreira dos filhos, que "soltam com dinheiro nas cidades para estudar, sem preocupar-se em formá-los na verdadeira responsabilidade, sem o educarem num clima de verdadeira liberdade, a fim de que cumpram as suas obrigações para com Deus e com a sociedade". Ele insiste que os pais devem seguir seus filhos "com solicitude e energia", para evitar tragédias e crises e para que estes sejam "sua honra na vida, seu consolo na velhice e seu prêmio na eternidade" (grifos do próprio autor). Retoma mais uma vez o exemplo da sagrada família e o uso do número três, como meios de reforçar a questão da honradez na terra e da salvação pela eternidade.

A manutenção da família, unida no lugar de origem, agora Pedrinhas Paulista, a pequena Itália construída com o trabalho dos imigrantes sob sua orientação, é a solução para manter a identidade local da rica e próspera comunidade italiana, por isso o padre exorta os fiéis a cumprirem seu dever para que, além das comodidades materiais, cada lar seja "um verdadeiro ninho de amor, de felicidade e de paz entre todos os seus membros".

Dom Ernesto muda de língua, mas a entoação de seu discurso é sempre a mesma. Ele busca agora preservar uma outra identidade, não mais a dos "emigrantes", mas a dos pedrinhenses.

Os discursos de padre Ernesto, repletos de axiomas e formulados com estruturas paratáticas e formas verbais imperativas, além das muitas referências à comunidade como um todo pelo uso de "aqueles que, as famílias, etc.", caracterizam seu discurso de pregador e fundador da Missão 
de cura de Pedrinhas, não só como um discurso religioso, mas também como o de um guia político-ideológico disposto a mostrar os caminhos para os "emigrantes italianos" na nova pequena Itália brasileira.

Dom Ernesto, contudo, não se limitou ao discurso, mas procurou criar um ambiente italiano de vários modos. Uma das marcas deixadas pelo padre são os ciprestes plantados na frente do cemitério de Pedrinhas e da Igreja, os quais remetem à sua aldeia de origem, sendo a viva representação de uma característica italiana na paisagem do lugar.

A importância dos ciprestes está presente nos relatos a seguir e denota o quão preciosos foram para o padre e para toda a comunidade, como elementos que mantêm um elo direto com a luta pela adaptação do próprio imigrante na terra prometida e o desejo de dar-lhes um pouco da paisagem italiana.

( ) lui ha portato le sementi, è, le sementi ha portato, ma non hanno preso molto bene ( ) son morti più della metà perchè c'era 'na malattia che avevano preso, so che ... non era il vero cipresso ... dopo qua è stato trovato il cipresso, adattato a questo e allora adesso sono quelli che sono qui ( ). Ma ha combattuto tanto Don Ernesto perché non erano abituati, i cipressi erano abituati al clima di là di San Donà di Piave ... il freddo...7

( ) lui li ha portati, poi ne portava uno, due in ogni famiglia per ricordare dell' Italia, perché lui aveva molta tradizione ( ) lui voleva solo che restassi uma colonia italiana...8

"Emigrante" como seus compatriotas, Dom Ernesto enfrenta o mesmo sofrimento dos companheiros, portanto, sente como sua aquela colônia e deseja uma pequena Itália para os imigrantes e para si. A religião e a educação são os principais instrumentos do padre para atrair os fiéis: as missas em italiano e o ensino da língua italiana no jardim da infância foram elementos fundamentais na tentativa de manutenção de uma identidade italiana, embora os imigrantes provindos de diversas regiões da Itália logo começassem a fazer uso do que chamamos de interlíngua ${ }^{9}$ para a comunicação (Berruto, 1998:42).

Ainda hoje podemos observar nos testemunhos orais dos italianos a forte presença de elementos do discurso do padre fundador, traços marcantes na construção de uma identidade italiana pedrinhense. É a união familiar, os bons filhos junto aos pais, o trabalho e a repulsa contra quem não gosta de trabalhar, como se pode verificar na fala orgulhosa do testemunho a seguir:

... i bambini crescendo mio marito lavorando abbiamo lavorato tutti perché io son(o) una persona (che) mi piace molto lavorare ah (quanto però) io (lo) dico sempre mi

7. Entrevista concedida em julho de 1999 - "( ) ele trouxe as sementes, é, trouxe as sementes, mas não pegaram muito bem ( ) morreu mais da metade porque pegaram uma doença, sei que ... não era o verdadeiro cipreste ... depois, aqui, foi encontrado o cipreste, adaptado a isso e então agora, são aqueles que estão aqui [os adaptados] ( ). Mas Dom Ernesto lutou tanto, porque não estavam acostumados, os ciprestes estavam acostumados ao clima de lá, de San Donà di Piave ... o frio ". Tradução nossa.

8. Entrevista concedida em julho de 1999 - "( ) ele os trouxe, depois levava um ou dois para cada familia para lembrar-se da Itália, porque ele tinha muita tradição ( ) ele queria somente que ficasse uma colônia italiana ( )". Tradução nossa.

9. Por interlingua entendem-se variedades lingüísticas jả empobrecidas e reduzidas no léxico, na morfologia e na sintaxe. 
piace solo chi lavora e chi è vagabondo non è per me ( ) e la vita è andata cosi di di di di sofrimento (in) comincio ma dopo (guardi) io ho avuto i figli che sono stati molto buoni sempre ubbidiscono sempre lavorando col padre la madre tutti $\mathrm{i}^{10}$

Na mesma entrevista, a senhora continua a narração sobre a coragem que foi necessária para enfrentar as dificuldades de adaptação ao novo lugar:

... ma (̀̀) ormai a gente tá enfrentando a gente tem que ter coragem de enfrentar la vita ma chè è stato duro è stato ( ) e allora grazie a Dio abbiamo enfrentato lavorato sempre andato avanti ( ) è la vita è una lotta così ( $)^{11}$

Palavras como trabalho, sofrimento, coragem, enfrentar, obediência, sacrificio eluta, que fazem parte dos sermões de Dom Ernesto, são recorrentes nos testemunhos dos italianos de Pedrinhas.

No testemunho a seguir, palavras como coraggio, soppravivere, enfrentar, appoggiarsi a figura de Dom Ernesto revelam-se como elementos primordiais na então Colônia e até os dias atuais:

( ) abbiamo arrivato qui non abbiamo trovato niente un poco di strano l'abbiamo trovato ma la volontà il coraggio dell'emigrante quando disradica la la dalla come si dice radice vecchia enfrenta tutto ... adesso chi ha fatto il proposito di dire "no qui c'è come soppravvivere" ( ) ... e allora siamo siamo procurato di tener coraggio di appoggiarsi l'uno all'altro ... abbiamo avuto un padre veneziano di San Donà di Piave Don Ernesto quello lì ha preso le redi [redini] e ha mantenuto perchè io dico sempre "grazie a "sto Don Ernesto che oggi Pedrinha esiste" perchè lui è venuto come missionario come padre spirituale e ha fatto la parte di padre ha fatto la parte da console ha fatto la parte da padre di famiglia ... il disanimo è stato grande ... la propria situazione dell'emigrante procura sempre di abbracciarsi uno all'altro ... quello che è successo in Pedrinha o eravamo abruzzesi oveneziani o siciliani nasceva l'amicizia sulla prima vista non c'era ... ci siamo uniti ... no non c’è stato 'na separazione di razze o di regione c'abbiamo procurato sempre di aiutarsi di consigliarsi di mantenerci quanto più uniti porque solo così podevamo soppravvivere ...

Sì sì oggi si continua della stessa maniera perchè il tempo è passato ci siamo uniti sempre di più abbiamo costruito sempre di più ... ( ) s’è costruito Pedrinha ... ( ) tutto con l'unione del popolo ( ) sentivamo tutta la stessa necessità tutto lo stesso desiderio di tenere qualcosa di meglio era ... il padrone del paese uno animava da una parte e lui si animava e si tira avanti così né? passiamo qualcosa nostra ai nostri figli ai nostri nipoti ... ( ) la radice non si può perdere perchè se no loro domani ri-

10. Entrevista concedida em julho de 2000 - "as crianças que cresciam meu marido que trabalhava todos trabalhamos porque eu sou uma pessoa (que) gosta muito de trabalhar ah (quanto porém) eu falo sempre gosto só de quem trabalha e quem é vagabundo nāo tem vez ( ) e a vida foi assim de de de de sofrimento (no) início mas depois olha eu tive os filhos que foram muito bons sempre obedecem sempre trabalharam com o pai a mãe todos ( )". Tradução nossa.

11. Entrevista concedida em julho de 2000 - "mas (é) a gente tá enfrentando a gente tem que ter coragem de enfentar a vida mas que foi duro foi ( ) e então graças a Deus enfrentamos trabalhamos sempre fomos em frente ( ) é a vida é uma Juta assim ( )”. Tradução nossa. 
peto quando si domandano non si ... non sanno chi sono e la grande preoccupazione e la grande responsabilità della persona anziana penso io è giustamente quello di passare alla gioventù l'avventura quello che s’è passato, perchè siam venuti qui perchè certi figli oggi dicono che “i genitori nostri sono stati ignoranti c'hanno portati a 'sto Brasile perchè não sei que não sei que perchè in Italia c'era questo e c'era quell'altro" si ... c'era in Italia ma mancava il principale perchè l'Italia nessuno lo può mettere in dubbio che è uno dei più belli paesi del mondo ma "la bellezza non riempie la pancia" come si dice nel dialetto nostro è vero? ( ) 'sti vecchi 'sti genitori dovevano far qualcosa e allora la gente l'ha sentuto alla pelle la responsabilità e ... cosa sentivano 'sti vecchi nostri e allora noi lo sappiamo ... li passiamo ai figli ... ma quelli che non c'hanno detto il perchè hanno venuto qui in Brasile o a ' $n$ altro posto del mondo non lo sanno accusano i genitori di averli tirato dall'Italia perchè l'Italia oggi è un giardino ... invece la realtà non è quella perchè se si stava bene lì se i nostri padri i nostri genitori avevano tutto per poter soppravvivere la famiglia uscivano di li prá que? Non c'era motivo ( ) ${ }^{12}$ (grifos nossos)

Para poder compreender a relação entre língua e espaço e o poder da fala do padre sobre o pedrinhense é fundamental fazer uma análise da variedade de língua italiana existente em Pedrinhas Paulista. Note-se, no testemunho acima, a ênfase dada à união do grupo que, de acordo com o relato, agiria como uma grande família unida, graças à força moral incutida por Dom Ernesto. A língua, para o italiano pedrinhense, passa a ser uma língua própria, única, como única é a comunidade pedrinhense, formada pelos "emigrados e exilados" guiados pela força e pelos ideais de Dom Ernesto. A força que emana de seus sermões, repetidos e constantemente reelaborados, reforça a idéia inicial da manutenção de um povo unido e coeso em sua moral, costumes e língua.

A antiga Colônia de Pedrinhas, inserida num ambiente estritamente rural em seu início, hoje cede lugar a um espaço heterogêneo composto por mansões que ladeiam a avenida principal da pequena cidade e por novos bairros de casas populares, o que denota como se compõe a sociedade pedrinhense. Há, ainda, numa simbólica representação de avanço urbano, dois prédios inacabados.

12. Entrevista concedida em julho de 1999 - “( ) chegamos aqui não encontramos nada achamos um pouco estranho mas a vontade e a coragem do emigrante quando é arrancado a a da como se diz da velha raiz enfrenta tudo ... agora quem veio com o propósito de dizer “não aqui há como sobreviver" ( ) e então procuramos ter coragem de apoiar-nos um ao outro ... tivemos um padre veneziano de San Donà di Piave Dom Ernesto aquele lá tomou as rédeas e manteve porque eu sempre digo "graças a esse Dom Ernesto que Pedrinhas existe hoje" porque ele veio como missionário como pai espiritual e fez a parte de padre fez a parte de cônsul fez a parte de pai de fanília ... o desânimo foi grande ... a própria situação do emigrante [que] procura sempre abraçar-se um ao outro ... o que aconteceu em Pedrinhas ou éramos abruzeses ou venezianos ou sicilianos nascia a amizade à primeira vista ... não havia ... nos unimos ... não não houve uma separação de raças ou de regiāo procuramos sempre ajudar-nos aconselhar-nos manter-nos sempre unidos porque só assim podiamos sobreviver ... sim sim hoje se continua da mesma maneira porque o tempo passou nos unimos sempre mais construimos sempre mais ... ( ) construiu-se Pedrinhas ... ( ) tudo com a uniāo do povo ( ) sentíamos todos a mesma necessidade todos o mesmo desejo de ter algo melhor era ... o dono da cidade [refere-se ao padre] um animava de um lado e ele se animava e se vai em frente assim né? passamos algo nosso aos nossos filhos aos nossos netos ... ( ) a raiz não se pode perder porque senão eles amanhã repito quando se perguntam não se ... não sabem quem são e a grande preocupação e a grande responsabilidade dos mais velhos penso eu é justamente o de passar à juventude a aventura o que se passou porque viemos para cá porque certos filhos hoje dizem que "os nossos pais foram ignorantes nos trouxeram para este Brasil porque não sei que não sei que porque na Itália tinha isso e tinha aquilo" sim ... havia na Itália mas faltava o principal porque a Itália ninguém pode duvidar que é um dos mais belos países do mundo mas "a beleza não enche a barriga" como se diz no nosso dialeto, não é verdade? ( ) esses velhos esses pais tinham que fazer alguma coisa e então a gente sentiu na pele a responsabilidade e ... o que sentiam esses nossos velhos e então nós o sabemos ... passamos aos filhos ... mas aqueles que nāo lhes disseram [o] por quê vieram ao Brasil ou a um outro lugar do mundo não o sabem [e] acusam os pais de tê-los tirado da Itália porque a Itália hoje é um jardim ... ao contrário a realidade não é aquela porque se se estava bem lá se nossos pais tinham tudo para que a família pudesse sobreviver por quê sairiam de lá, prá que? nāo havia motivo ( ). Tradução nossa. 
As mudanças no ambiente urbano de Pedrinhas, ocorridas no decorrer desses anos, evidenciam uma mudança profunda no imaginário das pessoas. A invenção da Pátria, processo que se iniciou com a fundação da Colônia, culmina com a construção dos símbolos atuais, como o Memorial e o Portal da cidade. Tais elementos, inseridos no espaço pedrinhense, ajudam a perpetuar uma visão cada vez mais artificial e estereotipada da Pátria, mas representam, no imaginário local, o retrato da pequena Itália.

Podemos dizer que, numa comunidade estruturada como Pedrinhas, a memória do imigrado não é individual: há traços de memórias individuais que se somam na memória coletiva dos integrantes dessa comunidade e formam, assim, um entrelaçamento de idéias e ideais em que cada um deixou sua marca pessoal e a integrou aos anseios do grupo e da família.

A língua é parte integrante dessa memória e dos testemunhos orais dos italianos de Pedrinhas; nela se percebe uma maneira particular de comunicação, construída de acordo com o dialeto de origem, da facilidade individual de assimilação do italiano falado pelo padre e pelos funcionários da Companhia e de seus contatos com a Itália atualmente. Os imigrantes adultos chegaram a Pedrinhas falando cada um seu dialeto natal. A língua italiana, que supostamente deveriam ter trazido da Itália e à qual se sentem ligados por afeto profundo, para eles, pelo menos em parte, foi construida em Pedrinhas.

Na medida em que se evocam lembranças das testemunhas que chegaram a Pedrinhas ainda adolescentes ou adultos jovens, as recordações trazem à tona fragmentos de língua italiana, porque, quando crianças, ainda na Itália, eles freqüentaram a escola. Por isso, percebemos em seu discurso, depois de tantos anos, uma prevalência do italiano sobre o dialeto; em seus testemunhos, as interferências dialetais são mínimas no plano do léxico, mas notamos certa dificuldade na construção das frases. Talvez, por isso, as noções repetidas pelo padre em seus sermões sejam tão presente nas falas dos pedrinhenses. Os conceitos que ele elaborou de união, fraternidade e coragem para a fundação e manutenção de um espaço italiano mantêm-se na memória como traço de italianidade, de herança da terra natal.

Os primeiros resultados da pesquisa sobre a língua dos imigrados italianos de Pedrinhas Paulista destacam questões relativas à existência de variedades de língua italiana na cidade de São Pauloe em diversos locais próximos ou distantes da capital paulista. Dados importantes num momento em que lingüistas do mundo todo estão envolvidos em estudar as formas e os processos que as línguas sofreram para transformarem-se em variedades lingüísticas diferentes ou até mesmo em outras línguas. São estudos que merecem destaque, não somente do ponto de vista lingüístico, mas também social, a fim de manter-se ou recuperar-se a peculiaridade dessas comunidades.

Na língua falada em geral, sem diferenciar nível de instrução dos interlocutores, pode-se observar que há traços genéricos que contrastam radicalmente dos da língua escrita ou da língua falada transposta para a escrita. Tais traços enfocam a situação e o momento no qual ocorre a conversação entre dois ou mais interlocutores e o grau de interação entre eles. Para que a conversação se 
realize deve haver identidade temporal, mas não necessariamente identidade espacial (notem-se os telefonemas, válidos pela espontaneidade expressiva que permitem ao interlocutor). A língua falada numa situação espontânea tende a realizar um discurso não elaborado, com repetições de palavras ou de frases e predominância de coordenação e pausas, a fim de dar tempo ao interlocutor de organizar suas idéias. Tal discurso pode ser reestruturado durante a conversação, em qualquer momento, sem prejudicar a coerência do assunto em questão.

Os testemunhos dos imigrados pedrinhenses são um claro exemplo de discurso não elaborado, apesar dos entrevistados saberem, um pouco antes da entrevista, o assunto a ser tratado. Embora houvesse essa consciência, a interação entre documentador e informante foi a mais natural possivel.

A partir do momento em que lhes se colocam as perguntas relativas às lembranças da viagem, da chegada e da adaptação, iniciam a própria narrativa: constroem e reconstroem constantemente, revelando os limites de quanto resta de seu italiano, perdido, em parte, todavia arquitetado e rearquitetado paralelamente à construção e reconstrução de sua vida e de uma Itália inventada e imaginada por eles e por seu guia ideológico-espiritual em Pedrinhas Paulista.

Anna Giacalone Ramat, num de seus ensaios (1994:47), indica as grandes transformações sofridas pelo italiano com o contato externo, que, ao mesmo tempo, se amplia no espaço de abrangência da língua fora do país de origem. Outro dado importante é que o italiano, ou uma variedade dessa língua, torna-se veículo de ligação entre italianos provenientes de diferentes regiões da península.

Outra estudiosa da língua italiana fora da Itália, Camilla Bettoni, em pesquisa sobre Italianos na Austrália observa:

L' italofonia degli emigranti va comunque qualificata come non standard. Infatti la loro varietà più alta è l'italiano popolare, definito molto appropriatamente in questa sede con Berruto (1987:108) la 'varietà sociale dell'italiano [...] usata da/tipica di strati sociali bassi, incolti e semicolti'. D'altra parte l'italiano standard, praticamente assente nella realtà dell'emigrazione come bene d'uso, è pur sempre presente come ideale, con tutte le virtù - e tutti i difetti - di un modello che i pochi anni di scuola avevano imposto nei programmi ma non garantito in classe. (2002: 415)

Portanto, a língua que se ouve hoje nos testemunhos dos italianos pedrinhenses não é uma pura e simples deformação da língua standard (e não se pode absolutamente tomar como modelo de comparação), tampouco é língua materna dos imigrados, mas é uma língua construída, num primeiro momento, no contato com o padre, como já mencionado.

Como diversos lingüistas já observaram em outros países de imigração italiana, na variedade de língua usada nas entrevistas de Pedrinhas Paulista a subordinação também é pouco utilizada. Há 
escassez de conjunções subordinadas, mas também coordenadas, como conclusivas e adversativas: 'quindi', 'dunque', 'tuttavia', 'pertanto', ao passo que é muito freqüente o uso de 'ma' e 'perché', o que torna a narrativa menos comprometedora do ponto de vista sintático. Entre outras coisas não se pode esquecer que a característica da coordenação das frases na língua falada pertence a qualquer língua, até mesmo quando se trata de língua culta.

$\mathrm{Na}$ fala dos italianos pedrinhenses, as reformulações em português-brasileiro/italiano e italiano/português-brasileiro refletem a dificuldade que os informantes têm para achar uma maneira adequada de expressar a idéia. Portanto, observa-se que há sempre a tentativa de esclarecer o assunto ao documentador, seja por meio de uma palavra ou frase em português-brasileiro e de sua reformulação (sempre em português-brasileiro), seja por meio de um termo de origem dialetal ou português-brasileiro e sua reformulação em italiano.

Os imigrados pedrinhenses reconhecem-se como italianos pelo uso da língua, apesar de a maioria ter plena consciência de que se trata de uma língua bastante misturada; reconhecem-se pelo espaço que criaram em seu imaginário, espaço reconhecidamente italiano. Sabemos que a língua materna nacional é a base da identidade de um povo e os pedrinhenses, reconhecendo-se como italianos pelo uso da língua, não perderam de todo sua identidade. Até hoje, quando falam sobre o assunto, não se consideram apenas vênetos, calabreses, abbruzzesi, mas italianos pedrinhenses que se entendem reciprocamente.

O exercício de elaboração e reelaboração do discurso dos imigrados de Pedrinhas Paulista constrói o seu patrimônio lingüístico italiano e é uma de suas vitórias sobre as dificuldades enfrentadas no momento em que eles se fixaram no Brasil. Entre tantos elementos que constituem a realidade cotidiana pedrinhense, a variedade interlingüística dos italianos dessa pequena cidade surge como uma das tentativas de manter sua identidade, elemento fundamental, a fim de que o homem tenha o sentimento de pertencer a determinado lugar.

Os pedrinhenses percebem que o espaço que construíram juntamente com Dom Ernesto, por meio da idealização de sua aldeia de origem, é um lugar com o qual se identificam plenamente e que, na sua visão, se tornou o paraíso reencontrado. A língua é o veículo de suas memórias, narradas e elevadas a mito, e a narrativa dos primeiros imigrantes italianos, elevada à fábula, permeia o ambiente e é repassado aos descendentes. Dessa forma, há uma concatenação de memórias, somam-se histórias de vida que são repetidas e reforçadas pelas gerações de netos e bisnetos nascidos em Pedrinhas Paulista. 


\section{Referências Bibliográficas}

BAKHTIN, M. Questōes de literatura e estética: a teoria do romance. 2. ed. São Paulo: Editora da UNESP/Hucitec, 1990.439p.

BAKHTIN, M., VOLOSCHINOV. Marxismo e filosofia da linguagem. 6. ed. São Paulo: Hucitec, 1992(a).

BERRUTO, G. Sociolinguistica dell'italiano contemporaneo. Roma: Carocci, 1998.

BETTANINI, A. Espaço e ciências humanas. Rio de Janeiro: Paz e Terra, 1982.

BETTONI, C. Italiano fuori d'Italia. In: SOBRERO, A. Introduzione all'italiano contemporaneo: la variazione egli usi. Bari: Laterza, 2002.

CARLOS, A. F. ALESSANDRI. (Org.) Os caminhos de reflexão sobre a cidade e o urbano. São Paulo: EDUSP, 1994.

A (re)produção do espaço urbano. São Paulo: EDUSP, 1994.

DE FINA, A. \& BIZZONI, F., a cura di. Italiano e Italiani fuori d'Italia. Perugia: Guerra, 2003.

DE MAURO, T. Storia linguistica dell'Italia unita. Bari: Laterza, 1991.

FÁVERO, L. L.; ANDRADE, M. L. C. V. O.; AQUINO, Z. G. O. Estratégias de construção do texto falado: a correçā.o In: Gramática do Português falado - volume V: Convergências. Campinas: Editora da UNICAMP, 1996.

HALBWACHS, M. A memória coletiva. São Paulo: Vértice, 1999.

NENCIONI, G. Di scritto e di parlato: discorsi linguistici. Zanichelli: Bologna, 1983.

ORLANDI, E. Discurso e texto: formulação e circulação dos sentidos. Campinas/SP: Pontes, 2001.

PALLOTTI, G. La Seconda Lingua. Milano: Bompiani, 1998.

PEREIRA, J. B. B. Italianos no mundo rural paulista. São Paulo: Pioneira, 1974.

Italianos no mundo rural paulista. 2. ed. São Paulo: EDUSP, 2002.

PERELMAN, C. e OLBRECHTS-TYTECA, L Tratado sobre a argumentação: a nova retórica. Trad. M. E. G. G. Pereira. São Paulo: Martins Fontes, 1996.

PRETI, Dino. Análise de textos orais. São Paulo: FFLCH/USP, 1993.

RAMAT, A. G. Il LIP e l'italiano fuori d'Italia. In: DE MAURO, T. Come parlano gli italiani. Firenze: La Nuova Italia, 1994.

TRENTO, A. Do outro lado do Atlântico. São Paulo: Nobel, 1989. 